\title{
ESTUDOS SOBRE A ALIMENTAÇÃO MINERAL DO ALGODOEIRO. II. DEFICIÊNCIAS DE MICRONU- TRIENTES NA VARIEDADE I. A. C. 11 *
}

\author{
J. R. SARRUge ** \\ H. P. $\mathrm{HAAG}_{\text {A* }}$ \\ E. Malavolta \\ W. R. Accorsi ***
}

\section{RESUMO}

\begin{abstract}
No sentido de se obter o quadro sintomatológico da carência dos micronutrientes, assim como dados analíticos, cultivou-se em solução nutritiva purificada plantas de algodão da variedade I. A. C. 11. Foi obtido o quadro sintomatológico das carências de B, Cu, Fe, Mn, Mo e Zn. A análise química das folhas novas afetadas pelas carências apresentou os seguintes valores $(\mathrm{ppm}): \mathrm{B}=33 ; \mathrm{Cu}=4,8 ; \mathrm{Fe}=238$; $\mathrm{Mn}=8,7 ; \mathrm{Mo}=0,12: \mathrm{Zn}=25,2$.
\end{abstract}

\section{INTRODUÇAOO}

A cultura do algodoeiro acha-se espalhada pelos quatro cantos do mundo adquirindo por isso grande importância econômica. Muitos trabalhos já foram feitos sobre a alimentação mineral dessa malvácea como se pode verificar através da revisão da literatura publicada por MALAVOLTA et al. (1962); entre as publicações disponíveis não foi possível encontrar, porém, nenhuma que estudasse os sintomas e os efeitos das deficiências de micronutrientes no algodoeiro de modo razoavelmente completo. Embora formando uma chave bastante útil para a identificação dos sintomas de carência mineral, a contribuição de MENDES (1960) só menciona o ferro entre os micronutrientes estudados. Outros trabalhos só cuidaram das deficiências de macronutrientes (o de COOPER, 1939, é exemplo) ou disseram apenas de sintomas de carência de micronutrientes observados em condições de campo.

$\mathrm{O}$ presente trabalho teve por isso duas finalidades principais:

* Entregue para publicação em 1/10/73.

** Departamento de Química - ESALQ.

*** Departamento de Botanica - ESALQ. 
a) obter um quadro completo das deficiências de micronutrientes no algodoeiro o qual serviria para a identificação de anomalias dessa natureza em condições de campo;

b) obter dados de análise de folhas que poderiam tornar mais seguro o diagnóstico visual.

\title{
MATERIAL E MÉTODO
}

\section{Solução nutrifiva}

As soluções estoque portadoras de macronutrientes foram purificadas por uma modificação da técnica de HEWITT (1952, p. 191). Os micronutrientes, em vista das pequenas concentrações usadas e da pureza das drogas, não foram previamente purificadas. Empregou-se água destilada e depois desmineralizada.

Os elementos foram fornecidos nas seguintes proporções:

$$
\mathrm{P}-0,5 \mathrm{ml} \text { de uma solução de } \mathrm{NaH}_{2} \mathrm{PO}_{4} \mathrm{M} \text { por litro }
$$

$\mathrm{K}$ e $\mathrm{N}-1,25 \mathrm{ml}$ de uma solução $\mathrm{KNO}_{3} 2 \mathrm{M}$ por litro

Ca e $\mathrm{N}-1,25 \mathrm{ml}$ de uma solução $\mathrm{Ca}\left(\mathrm{NO}_{3}\right) 2 \mathrm{M}$ por litro

$\mathrm{Mg}$ e $\mathrm{S}-1 \mathrm{ml}$ de uma solução $\mathrm{MgSO}_{4} 0,75 \mathrm{M}$ por litro

Micronutrientes - doses recomendadas por HOAGLAND \& ARNON (1950).

O ensaio fei feito com 6 repetições, havendo os seguintes tratamentos:

$$
\begin{gathered}
\text { Vasos } \\
1-6 \\
7-12 \\
13-18 \\
19-24 \\
25-30 \\
31-36 \\
37-42
\end{gathered}
$$

\author{
tratamento \\ menos boro \\ menos cobre \\ menos zinco \\ menos molibdênio \\ menos ferro \\ menos manganês \\ completo
}

\section{Material vegetal}

As sementes de algodoeiro da variedade IAC 11 foram desinfetadas com $\mathrm{H}_{2} \mathrm{SO}_{4}$ e postas a germinar em vermiculita umidecida com água desmineralizada. As plantinhas tendo apenas folhas cotiledonares foram transplantadas para vasos de polietileno de 1,5 1 de capacidade vasos esses pintados externamente com uma camada de tinta preta e sobre esta, outra de esmalte branco. A colheita se fez 3 meses e meio depois do plantio. 0 ensaio foi conduzido no interior de casa de vegetação dispondo de sistema para resfriamento e renovação de ar. 


\section{Dados colhidos}

Durante o transcorrer do experimento foram feitas observações do desenvolvimento das plantas; os sintomas aparecidos foram registrados em fotografia branco e preto, coloridas e em aquarelas.

Findo o ensaio foram colhidas folhas para obtenção de cortes para exame anatômico.

Depois de medir-se a altura do caule e o comprimento das raízes o material foi seco a $70-80^{\circ}$ e pesado; as folhas secas e trituradas foram submetidas à determinação de micronutrientes pelas técnicas descritas por JOHNSON \& ULRICH (1959).

\section{RESULTADOS E DISCUSSAO}

\section{Sintomas externos}

Os sintomas de deficiência se manifestaram na seguinte ordem: ferro, boro, manganês, zinco, molibdênio, cobre; quer isto dizer que a falta de ferro foi a primeira a se manifestar externamente e a carência de cobre a última a aparecer.

\section{Boro}

Gema terminal de coloração escura, em fase de necrose. As duas folhas situadas abaixo, pequeninas, escuras e necrosadas. A 3. ${ }^{\mathrm{a}}$ folha, de tamanho médio, com manchas cloróticas internervais, distribuidas por todo o limbo. Nas imediações da base ocorrem algumas manchas marrons e algumas pretas e os bordos do limbo permanecem enroladas. As duas folhas que se seguem, adultas (maduras), apresentam lodos de limbo recurvados para baixo (face inferior). As últimas folhas, próximas à inserção dos cotiledones, manifestam sintomas de clorose. Com o progredir dos sintomas, as folhas mais afetadas exibem a suberização parcial das nervuras principal e secundária, principalmente junto à base, a qual pode estender-se pelo pecíolo. Nessa fase, a planta já mostra o fenômeno do superbrotamento que se processa após a morte da gema terminal.

\section{Cobre}

Os sintomas de carência de cobre merecem destaque especial já que a sua descrição não foi encontrada na literatura consultada.

Plantas com flores. Queda das duas folhas superiores, portadoras de uma necrose pardacenta; estípulas dessecadas ainda presas à planta. As folhas inferiores, mais maduras, com pecíolo arqueado para baixo, fazendo, entretanto, junto à inserção do limbo, uma pequena curvatura para cima, mantendo, desta forma, o limbo em posição enclinada. Em todas as axilas da periferia (bordos) uma necrose parda que caminha para o centro da lâmina. De um modo geral a coloração das folhas é de um verde mais claro, 
havendo, nas mais maduras, pequeninas áreas cloróticas, talvez não devidas à falta de cobre.

\section{Ferro}

As plantas revelam menos crescimento que as plantas testemunhas. Suas folhas se apresentam cloróticas. Nas novas, a clorose se revela sobre todo o limbo. Nas mais maduras, a clorose é internerval, permanecendo apenas em volta das nervuras uma faixa verde, à guisa de frizo. Por essa razão, nervuras se tornam nítidas sobre a lâmina foliar.

\section{Manganês}

Nas folhas superiores observa-se um clorose internerval e as nervuras envolvidas por uma bainha escura. Sobre as áreas cloróticas surgem pequeninos pontos, de coloração marron. Planta de porte pequeno.

\section{Molibdênio}

Limbo de bordos arqueados para baixo. Plantas com florescimento precoce e algumas com frutos. Faixas cloróticas, internervais, partindo dos bordos em direção ao centro nas folhas maduras, e, em início, nas novas. As folhas mais baixas da planta, portanto, as mais maduras, inteiramente amareladas. Ao redor de cada nervura, à guisa de bainha, há um frizo verde, bem estreito.

\section{Zinco}

Os sintomas iniciais manifestam-se nas folhas novas e consistem de manchas cloróticas internervais, sobre as quais surgem pequeninas manchas punctiformes, escuras.

As folhas mais maduras, inferiores, manifestam uma clorose que se propaga da periferia para o centro do limbo, por entre as nervuras. Em algumas plantas, as folhas inferiores revelam, além da clorose, manchas crestadas, de forma e tamanho variaveis e que resultam da fusão, por crescimento, de manchas pequenas, punctiformes e de coloração marron. No estágio final, elas se tornam pardas.

\section{Sintomas internos (anatômicos)}

\section{Boro}

Do exame anatômico dos cortes, verifica-se que o limbo apresenta, de espaço a espaço, ligeiros estrangulamentos, oferecendo ao conjunto um aspecto sinuoso.

A carência, isto é, a ausência de B provoca uma clorose generalizada e afeta, ainda, a forma e o tamanho dos cloroplastos e consequentemente o seu número. A impressão que se tem é que os cloroplastos sofrem fragmen- 
tações diversas. Via de regra. eles estão esparsos, ocorrendo, entretanto, massas amorfas, cloróticas, resultantes da aglutinação de alguns cloroplastos.

Os tecidos ainda não atingidos pelos sintomas apresentam aspecto normal. Nas áreas em que a necrose se manifesta, além da desorganização histológica, como é óbvio, observa-se o escurecimento do conteúdo celular. A presença de gases acumulados pode ser identificada em certos trechos, que se mostravam escuros, como que velados por uma sombra intensa. Todavia, facilmente se eliminam os gases, tratando-se os cortes com álcool absoluto.

Examinamos, ainda, a estrutura das nervuras portadoras dos sintomas de suberização e pudemos comprovar, no mesófilo adjacente a elas, a presença de numerosos corpúsculo de matérıa graxa, ora esféricos ora globosos, de vários tamanhos, os quais se colorem, intensamente, de vermelho com o Sudan IV. As membranas suberizadas também adquirem a coloração vermelha quando submetidas à ação do reativo mencionado.

\section{Cobre}

As observações efetuadas nos cortes praticados nas áreas em fase de necrose mostram que os cloroplastos do tecido paliçádico se apresentam descorados, como que aclorofilados, esbranquiçados alguns, e com acentuadas alterações na forma e no tamanho, formando, ainda, por aglutinação, massas irregulares. Nos trechos mais afetados, o acúmulo de gases é grande, chegando a mascarar as celulas. Os gases também se acumulam no lacunoso.

A clorose atinge, ainda, os cloroplastos do lacunoso. Ela é mais acentuada nos trechos abaixo do paliçádico que se mostram afetados pelos sintomas mencionados. As alterações dos cloroplastos, todavia, no lacunoso, não muito profundas, embora ocorram grãos ovóides, alongados, elepsóides, etc., ora esparsos, ora aglutinados.

\section{Ferro}

Como se sabe a falta de ferro gera uma clorose progressiva, ao mesmo tempo que os cloroplastos se modificam, tanto na forma, como no tamanho e por cnseguinte, $\mathrm{n}$ número. Em geral, na clorose avançada, os cloroplastos são pequenos e podem ser grânulos, bastonetes, poliédricos, etc., isolados, esparsos, ou reunidos em certo número na formação de massas amorfas.

Podemos registrar a presença de gases acumulados entre as células em certos trechos do mesófilo.

\section{Manganês}

Procedendo-se ao exame anatômico das áreas portadoras dos sintomas, comprova-se o processo clorótico e as alterações dos cloroplastos, os quais, além de modificados na forma se aglutinam em número maior ou menos e constituem, assim, massas irregulares, de tamanhos vários. A clorose se acen- 
tua em certos trechos, o conteúdo celular se modifica na cor, tornando-se pardo avermelhada, surgindo assim pontos marrons sobre as mencionadas áreas cloróticas internervais do limbo. Em estág os mais adiantados, sobre. vem a necrose dos tecidos. São também frequentes os trechos do mesófilo escurecido pelos gases acumulados, principalmente no palhiçádico.

\section{Molibdênio}

Procedendo-se ao exame microscópico dos cortes, comprova-se na área dos sintomas e suas imediações, que os cloroplastos estão recobertos de amido, em grau diverso, e isto tanto no tecido paliçádico como no lacunoso, conforme se comprovou pelo reativo de Lugol. Os cloroplastos se transformam, pouco a puco, em autênticos grãos de amido, e o mesófilo em tecido de reserva, com suas células repletas daqueles plastos. Os maiores grãos encontram-se nas células do lacunoso. No paliçádico, cujas células são altas e estreitas, há uma mistura de grãos pequenos e grancies e de diversas formas.

Este fato contrasta com as observações feitas nas folhas de algodoeiro das plantas cultivadas na ausência dos demais micronutrientes, cujos cloroplastos experimentam modificações diversas, no tocante à forma, tamanho, coloração, etc.

O parênquima da nervura principal apresenta, por sua vez, em suas células, grande quantidade de grãos de amido típicos, de vários tamanhos; alguns se assemelhando aos da mandioca, e podem ser simples ou compostos, via de regra são maiores do que os formados no mesófilo, em virtude do acúmulo de amido nos cloroplastos. Nestas condições, o parênquima transforma-se em tecido de reserva.

\section{Zinco}

Observações anatômicas realizadas na região dos sintomas revelam alterações na morfologia dos tecidos paliçádicos e lacunosos, no conteúdo das células e particularmente nos cloroplastos. Estes, além da clorose, cujo grau de intensidade varia conforme o trecho observado, revelam variações na forma e no tamanho, podendo, por outro lado, formar massas amorfas ou, então, permanecer isolados. Comumente os cloroplastos assumem o aspecto de minúsculos grãos, ora esparsos pelas células, ora aglomerados.

Em certas zonas da estrutura, o conteúdo das células é pardacento, podendo anotar, inclusive, gases retidos nos espaços intercelulares e que emprestam aos tecidos um aspecto sombrio. Esses gases podem ser eliminados facilmente, juntando-se à lâmina algumas gotas de álcool absoluto.

Os trechos mortos, vão, pouco a pouco, se desorganizando, surgindo os trechos necrosados, responsáveis pelas manchas escuras do limbo.

\section{Dados de crescimento}

A tabela 3-1 dá o resultado das medições de altura e de comprimento do caule das plantas consideradas normais e das deficientes, médias das 6 re- 
petições. Verificou-se que o desenvolvimento radicular, em termos de comprimento das raízes não foi afetado pelos tratamentos; já a altura da planta foi menor em todas as plantas cultivadas com omissão de um micronutriente da solução nutritiva correspondente; as plantas com falta de boro e de zinco cresceram menos do que os algodoeiros, deficientes nos outros elementos considerados.

\begin{tabular}{lcc}
\hline Tratamento & $\begin{array}{c}\text { Comprimento } \\
\text { das raizes }(\mathrm{cm})\end{array}$ & $\begin{array}{c}\text { Altura do Caule } \\
(\mathrm{cm})\end{array}$ \\
\hline Completo & 32 & 54 \\
Menos boro & 27 & 34 \\
Menos cobre & 27 & 41 \\
Menos ferro & 33 & 42 \\
Menos manganès & 35 & 40 \\
Menos molibriênio & 31 & 41 \\
Menos zinco & 41 & 38 \\
\hline
\end{tabular}

Tabela 3-1. Dados médios de desenvolvimento do sitema radicular e do caule.

As variações na matéria seca, causadas pelos diversos tratamentos, podem ser apreciadas através do exame dos dados da tabela 3-2. Sob a denominação «parte aérea vegetativa» estão incluidas as somas dos pesos de: caule, caule secundário (apenas no caso das plantas com carência de boro), folhas (superiores e inferiores) e pecíolos; «parte aérea reprodutiva» sigifica a soma dos pesos da matéria seca das flores e dos frutos (brácteas, sementes e fibras). Os dados em questão são médias obtidas dividindo-se o peso das diversas partes por 6; não tendo sido feita a análise estatística desses dados, alguns dos comentários que se seguem devem ser considerados com a necessária reserva. 


\begin{tabular}{ccccccccc}
\hline $\begin{array}{c}\text { Parte da } \\
\text { planta (g) }\end{array}$ & Completo & -B & $-\mathrm{Cu}$ & $-\mathrm{Fe}$ & $-\mathrm{Mn}$ & $-\mathrm{Mo}$ & -Zn \\
\hline $\begin{array}{c}\text { Raíz } \\
\begin{array}{l}\text { Parte aérea } \\
\text { vegetativa }\end{array}\end{array}$ & 2,33 & 1,21 & 2,52 & 1,88 & 1,14 & 3,20 & 2,15 \\
$\begin{array}{l}\text { Parte aérea } \\
\text { reprodutiva }\end{array}$ & 8,05 & 5,60 & 6,72 & 8,19 & 5,27 & 8,24 & 6,48 \\
\hline TOTAL & 14,14 & 0,00 & 0,00 & 0,32 & 0,20 & 0,16 & 0,00 \\
\hline
\end{tabular}

Tabela 3-2. Produção média de matéria seca por planta nos diversos tratamentos.

Considerando-se a produção total de matéria seca verifica-se que o ef eito ia omissão dos micronutrientes foi, em ordem decrescente o seguinte:

Completo $>-\mathrm{Mo} \simeq-\mathrm{Fe}>-\mathrm{Cu}>-\mathrm{Zn}>-\mathrm{B} \simeq-\mathrm{Mn}$; quer isto dizer que: o desenvolvimento das plantas deficientes em molibdênio foi menor que o do algodoeiro cultivado em solução completa; as plantas com falta de boro e de manganês foram as que produziram menor quantidade de matéria seca. Usando-se critério semelhante para o exame dos dados relativos às quantidades de matéria seca das diversas partes consideradas, é possível estabelecer o seguinte quadro:

raiz

$-\mathrm{Mo}>-\mathrm{Cu}>$ Completo $>-\mathrm{Zn}>-\mathrm{Fe}>-\mathrm{B}>-\mathrm{Mn}$;

Parte aérea vegetativa

$-\mathrm{Mo} \simeq \mathrm{Fe} \simeq$ Completo $>-\mathrm{Cu} \simeq \mathrm{Zn}>-\mathrm{B}>-\mathrm{Mn}$;

Parte aérea reprodutiva

Completo $>-\mathrm{Fe}>-\mathrm{Mo}>-\mathrm{B} \simeq-\mathrm{Cu} \simeq-\mathrm{Zn}$.

É digno de nota o fato que as plantas deficientes em boro, cobre e zinco não apresentaram flores e, portanto, não completaram o ciclo vital já que deixaram de produzir sementes.

\section{Dados analíticos}

Devido à pequena quantidade de material seco existente não foi possível fazer as análises químicas em todas as partes do algodoeiro. Pelo mesmo motivo foi necessário juntar-se todas as folhas das seis plantas de cada tratamento a fim de proceder-se a determinação do teor dos micronutrientes considerados. Os resultados da Tabela $3-3$ devem por isso ser considerados com alguma cautela. Convém esclarecer que no caso das folhas deficientes só se determinou o elemento cuja omissão constituia o tratamento respectivo. 
Uma vez que as folhas foram misturadas para a análise é bem possível que 0 material deficiente por ventura encontrado no campo, apresente conteudo ainda menores de um ou de outro dos micronutrientes estudados. Parece lícito, porém, adiantar que os dados aqui apresentados tenham algum valor para ajudar o diagnóstico visual das deficiências por três motivos principais: (a) em primeiro lugar porque a diferença entre a composição das folhas consideradas normais e daquelas deficientes é bastante grande; (B) em segundo lugar porque os níveis achados no conjunto das folhas das plantas deficientes indicam uma deficiência real; assim sendo, a análise revelando valores ainda mais baixos deverá indicar, forçosamente carência do elemento considerados; (c) em terceiro lugar porque os níveis de micronutrientes encontrados nas folhas deficientes estão aceitavelmente próximos daqueles dados na literatura; esta observação se aplica apenas aos teores de boro (EATON, 1932) e de molibdênio (PETERSON \& PURVIS, 1961) já que não foram achados nas publicações disponíveis dados analíticos correspondentes aos níveis dos outros micronutrientes estudados.

\begin{tabular}{lcc}
\hline Elemento & \multicolumn{2}{c}{ Teor encontrado (p.p.m.) } \\
& nas folhas normais & nas folhas deficientes \\
\hline Boro (B) & 107 & 33 \\
Cobre (Cu) & 7,20 & 4,8 \\
Ferro (Fe) & 390 & 238 \\
Manganês (Mg) & 75,4 & 8,7 \\
Molibdênio (Mo) & 0,98 & 0,12 \\
Zinco (Zn) & 32,6 & 25,2 \\
\hline
\end{tabular}

Tabela 3-3. Niveis de micronutrientes encontrados nas folhas das plantas normais c. deficientes.

O teor percentual na folha de um determinado micronutriente omitido na solução nutritiva, considerado o nível normal como 100, aparece a seguir:

$\begin{array}{ll}\text { boro } & -31 \\ \text { cobre } & -67 \\ \text { ferro } & -61 \\ \text { manganês } & -12 \\ \text { molibdênio } & -12 \\ \text { zinco } & -77\end{array}$

Comparando esses dados com o efeito da omissão de micronutrientes na produção da matéria seca pode-se verificar que não existe um paralelismo muito 
bom. Em outras palavras: não há uma relação muito direta entre diminuição no teor de um elemento na folha e diminuição no crescimento causado pela sua omissão da solução nutritiva.

\section{CONCLUSOES}

1. O algodoeiro da variedade IAC 11 foi cultivado em solução nutritiva omitindo-se da mesma um micronutriente ( $\mathrm{B}, \mathrm{Cu}, \mathrm{Fe}, \mathrm{Mn}, \mathrm{Mo}, \mathrm{Zn}$ ) por vez.

2. A omissão de micronutrientes da solução nutritiva provocou diminuição no crescimento das plantas, avaliado pela quantidade de matéria seca produzida; o efeito da falta dos elementos se manifesta na segunda ordem decrescente:

Completo $>-\mathrm{Mo} \simeq-\mathrm{Fe}>-\mathrm{Cu}>-\mathrm{Zn}>-\mathrm{B} \simeq-\mathrm{Mn}$, o que significa que as plantas deficientes em $\mathrm{B}$ e $\mathrm{Mn}$ foram as que produziram menor quantidade de matéria seca.

3. As plantas deficientes em $\mathrm{B}, \mathrm{Cu}$ e $\mathrm{Zn}$ não chegaram a frutificar.

4. Foram obtidos sintomas nítidos de deficiência nas plantas que deixaram de receber um elemento qualquer.

5. A anatomia da folha foi alterada mais ou menos profundamente como consequência da falta dos micronutrientes. As modificações mais comuns dizem respeito ao número, tamanho, forma e distribuição dos cloroplastos. Notou-se ainda a presença de corpúsculos graxos no tecido foliar deficiente em $B$ e aquela de grãos de amido no caso da carência de molibdênio.

6. As folhas das plantas normais e das deficientes foram submetidas à análise química para determinar os teores de micronutrientes que indicam fornecimento adequado ou insuficiente dos mesmos.

7. Os sintomas visuais descritos podem servir de auxílio para a identificação de falta eventual de micronutriente no campo. $\mathrm{E}$ possível, entretanto, que na prática as deficiências se apresentem em grau menos acentuado o que dificultaria o serviço de diagnose. A análise química das folhas afetadas poderia, então, servir para tornar mais segura a diagnose visual.

\section{SUMMARY}

STUDIES ON THE MINERAL NUTRITION ON COTTON PLANT. II. MICRONUTRIENTS DEFICIENCIES.

1. Cotton plants were grown in water culture in the absence of each of six micronutrients (boron, copper iron, manganese, molybeenum and zinc) in turn.

2. The technique employed is described.

3. The effect of the treatments on growth, yeld and leaf composition is given. 
4. The deficiency symptoms are described.

5. The effect of lack oi micronutrients on leaf anatomy is also described.

6. The diagnostic volue of the data presented is discussed.

\section{L.ITERATURA CITADA}

COOPER, H. P. 1939 - Nutcitional deficiency symptoms in cotton. Proc. Soil Sci. Soc. Amer. 4: 322-324.

EATON, F. M. 1932 Soil Sci. $24: 301$ (original não consultado; cit em MALAVOLTA et al., 1962).

HEWITT, E. J. 1952 - "Sand and water culture methods in the study of plant nutrition". Comm. Bur. Fort. Plantation Crops Techn. Commun. 22. 240 págs., ilus.

HOAGLAND, D. R. \& D. I. ARNON. 1950 - "The water culture method for growing plants without soil", 32 págs. +7 figuras, Calif. Agric. Exptal. Sta. Cir. 347.

JOHNSON, C.M. \& A. ULRICH 1959 - "Analytical methods", Calif. Agric. Expeta. Sta. Bull. 766,78 págs., ilust.

MALAVOLTA, E., H. P. HAAG, F. A. F. MELLO \& M. O. C. BRASIL SOBR 1962 "On the mineral nutrition of some tropical crops", 155 págs. + 60 figuras International Potash Institute, Berne (Switezerland) 
